\title{
Waste rock dump rehabilitation to a new level-Telfer WD13 constructed mesa landform
}

\author{
J.A. Mifsud Care of Our Environment, Australia \\ E. Ryan-Reid Newcrest Mining Limited, Australia \\ M. Wealleans Newcrest Mining Limited, Australia
}

\begin{abstract}
Environmental expectations from the public have increased over the years. This has resulted in more demanding licence conditions for new mining operations. In addressing a ministerial condition to rehabilitate waste dumps to a condition that fits with the surrounding landforms, Newcrest's Telfer Operations embarked on a research and development programme to landscape waste dumps into mesas, a dominant landform in the region.

A series of trials were initiated on waste rock dumps to demonstrate that engineered mesas are potentially stable landforms and with the application of topsoil as a seed bank and growth medium can support vegetation. The experience from these trials was used in full-scale rehabilitation of waste dump WD13 at an abandoned mine pit.

From November to December 2008, WD13 was reshaped into a mesa landform and covered with a topsoil waste rock mix. The $30 \mathrm{~m}$ face of the waste rock dump was pushed into an upper slope at $16^{\circ}$ and the lower slope at $7^{\circ}$ and competent waste rock was added to the crest as a perimeter bund and to give the appearance of a duricrust. The final landscape closely resembled mesa landforms in the region.
\end{abstract}

Monitoring in October 2009, found the landform to be stable after exposure to several rain events, soil quality was unchanged and vegetation was establishing; Kapok Bush (Aerva javanica) an invasive weed, was the dominant emergent vegetation but many native species were also establishing. Spinifex was the dominant group of the native species.

\section{Introduction}

Newcrest Mining Limited (NML) has five operational sites located in New South Wales, Queensland, Western Australia, Indonesia and Papua New Guinea. The Telfer Gold Mine in Western Australia is an open-cut pit and underground operation producing gold and copper concentrate. Telfer was discovered in 1971 and mined by Newcrest from 1977 until 2000 producing around six million ounces of gold. In 2003, mining operations reopened supplying ore to a new processing plant that became operational in 2004 .

In addressing a ministerial condition to rehabilitate waste dumps to a condition that fits with the surrounding landforms, Telfer embarked on a research and development programme to landscape waste dumps into mesas, a dominant landform in the region. Earlier studies conducted by NML on traditional berm and bench rehabilitation at Telfer indicate that these methods are not the most suitable for the region nor are they compatible with natural landforms in the region.

Between 2005 and 2007, all waste rock dumps, tailings dams and heap leach dumps at Telfer were characterised for their geochemical and physical properties. This information combined with climatic data was used to develop a numerical model of a cover that will store rainfall (up to 1:100 years) and gradually release it. The aim is to retain enough moisture to support vegetation and significantly reduce infiltration through the waste dump and the possible release of managed acid rock drainage and heavy metals into the surrounding environment.

Conceptual engineering designs with various cover options were trialled between 2006 and 2008 on two waste rock dumps to evaluate the most appropriate construction methods and gain experience in engineering a stable mesa landform. 
These trials demonstrated that engineered mesas are potentially stable landforms and with the application of topsoil as a seed bank and growth medium will support vegetation. The most successful cover treatments from these trials were incorporated in full-scale rehabilitation of WD13 at an abandoned mine pit.

Mesa formations are characterised by:

- tabletop shaped formation

- rock armoured concave slopes consisting slope angles of approximately 7, 16, 25 and 39-60

- competent capping layer (duricrust)

- around 33\% vegetation cover, dominated by spinifex, as observed in the Telfer area.

From November to December 2008, WD13 was reshaped into a mesa landform. Prior to pushing the slopes, all the topsoil from the toe of the dump was harvested for later use. The thirty plus metre face of the waste rock dump was pushed into two slopes; the upper slope at $16^{\circ}$ and the lower slope at $7^{\circ}$.

The surface of the reshaped waste rock dump slopes was covered with a mix of waste rock and topsoil to provide armouring and growing medium for vegetation. The top of the dump was covered with hummocks of topsoil and waste rock material in a ratio of $1: 1$ and at around $0.5 \mathrm{~m}$ height. This was intended to minimise water ponding, provide microhabitats and reduce the amount of topsoil used.

Important lessons in engineering and soil science were learned from undertaking this work in this environment including:

- careful characterisation of the materials used in soil covers

- the design must consider geotechnical properties of waste rock (e.g. dispersive versus nondispersive)

- the drainage in these arid environments must be directed away from the slope crest

- the use of current survey data and dozers equipped with GPS and inclinometers is advantageous and reduces the dependence of field surveyors

- the topsoil and other soil cover materials must be free from weeds if practical accompanied by good hygiene and weed management

- dozer tracks on the slope should be minimised to reduce the likelihood that they may become preferential erosion pathways

- the use of hummocks for providing habitat must be balanced with the limited availability of seed bank and growth medium.

A five-year monitoring programme was initiated immediately after construction. This consists of permanent photo monitoring points to track regional changes in landform, transects for monitoring vegetation and erosion using ecosystem functional analysis (EFA) methods coupled with soil physico-chemical analysis to track stability and soil quality over time and soil moisture sensors coupled with a tipping bucket rain gauge to provide information on soil moisture for evaluating vegetation success and providing data for verifying the 'store and release' cover model. The monitoring results in 2009, almost one year after the earthworks, found that:

- landform mimicked natural mesas analogues

- EFA monitoring sites have been established to provide a scientifically based tool to determine when the rehabilitation has reached stasis

- spinifex was the dominant group of the native plants that emerged after the first rains, followed by acacias and grevilleas

- Kapok bush (Aerva javanica), which was already prevalent on the site was the dominant vegetation emerging after the first rains, but no new weed species were introduced

- Kapok bush is a weed that needs to be tracked and a management program implemented 
- no significant changes in soil $\mathrm{pH}$, salinity or organic matter content

- soil moisture sensors were detecting wetting fronts through the soil profile in response to rain events.

A full rehabilitation monitoring report will be generated in 2011 after the second year of monitoring.

\section{Site description}

\subsection{Regional setting}

The Telfer Operation is located in the Pilbara region of Western Australia, approximately $485 \mathrm{~km}$ south-east of Port Hedland and $140 \mathrm{~km}$ east of the Oakover River, which marks the western border of the Great Sandy Desert, Figure 1.

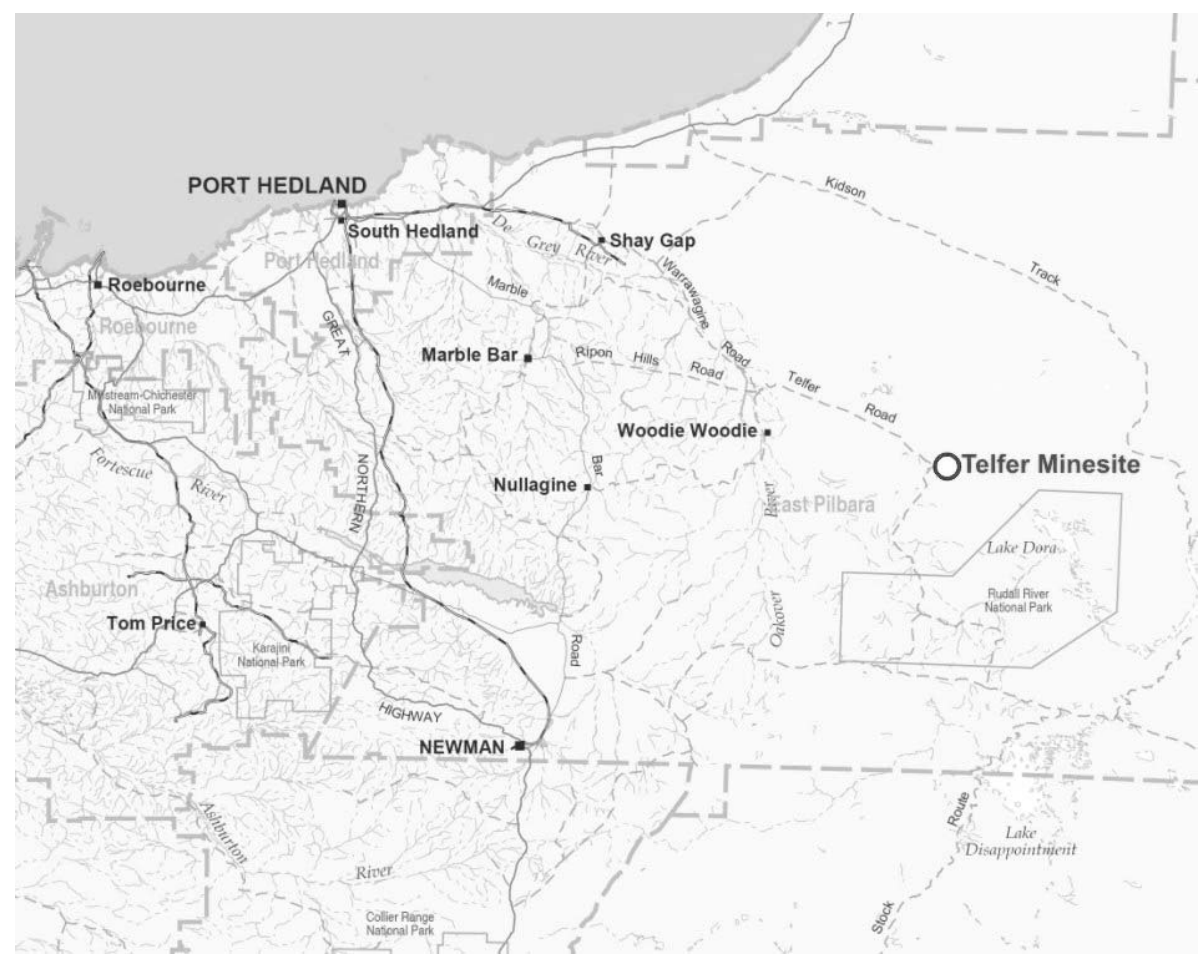

\section{Figure 1 Telfer mine site, Pilbara Region, Western Australia}

The dominant landforms around Telfer are mesa formations, stony hills, sand dunes and swales. Elevations range from around $360 \mathrm{~m}$ at the top of low stony hills to around $290 \mathrm{~m}$ in clay pan areas to the south. The Telfer area is located in the Canning Botanical district of the dry inland Western Australia (Beard, 1980). Flora consists predominantly of hummock grasslands with associated shrub and tree components predominantly Acacia, Eucalyptus, Hakea, Eremophila, and Cassia.

\subsection{Land use}

Telfer Gold Mine is on Crown Land and the region is not currently exploited commercially with the exception of mining and related activities. Regional mineral exploration by NML and others in adjoining tenements is currently being undertaken. The mine is located on Matru land, the nearest indigenous community is Punmu, approximately $120 \mathrm{~km}$ east of Telfer. One of the access routes to Rudall River National Park (located approximately $70 \mathrm{~km}$ south of Telfer) is through the Telfer tenement and passes within $50 \mathrm{~m}$ of WD13.

\subsection{Climate}

Climactic conditions in the Pilbara region including Telfer are characterised by low annual rainfall with two distinct seasons the wet season characterised by high temperatures and rain and the dry season with moderate 
temperatures and little or no rain, Figure 3. The mean daily evaporation rates generally exceeds the mean rainfall for most months except February and March, Figure 4.

\section{Australian Climate Statistics}

Location: 013030 TELFER AER0

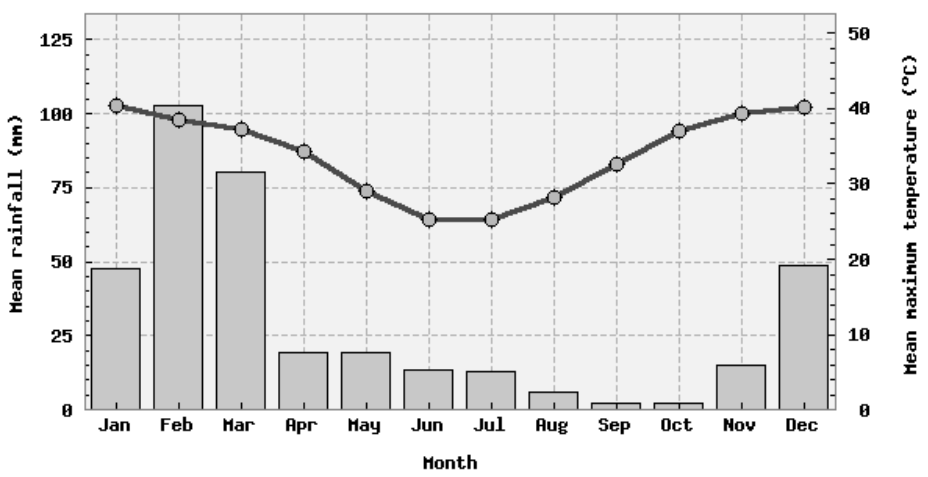

—013030 Mean rainfall (mm)

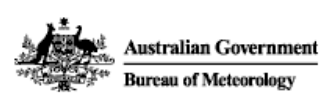

Created on Thu 10 Apr 2008 11:04 AM EST

Figure 2 Mean annual rainfall and maximum temperature, 1974-2008

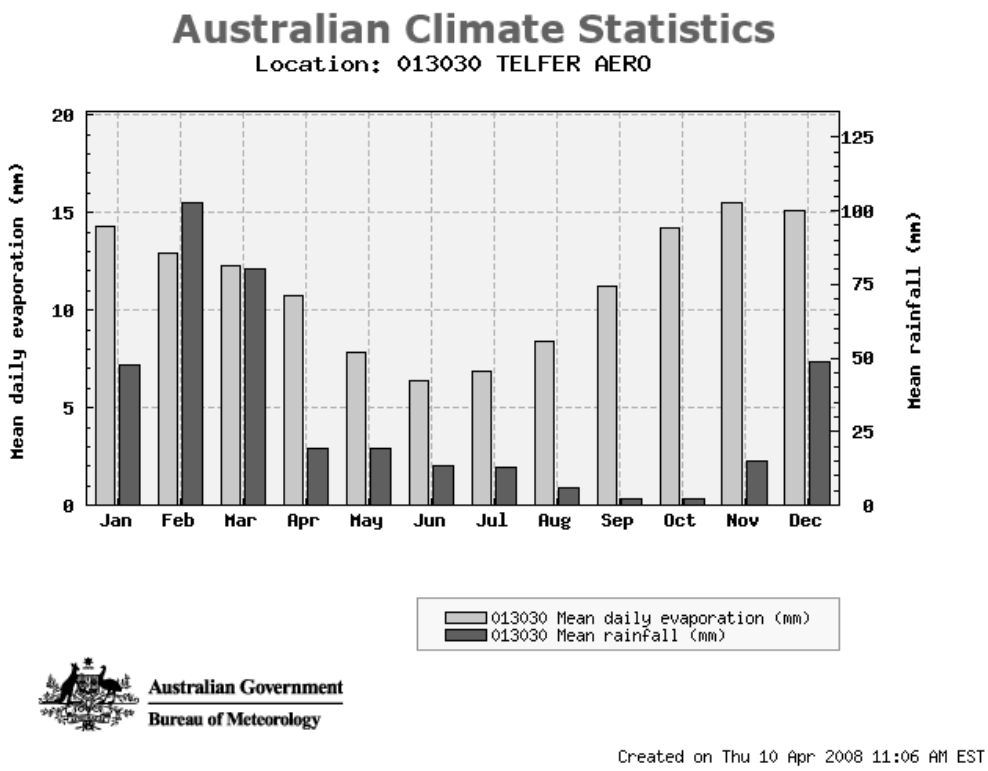

Figure 3 Mean daily evaporation and rainfall, 1974-2008

Annual rainfall is highly variable with a large percentage of the annual rainfall occurring over short periods. Rainfall intensity duration curves are typical of northern interior regions of Australia and show that, for a return period of 100 years, rainfall intensity varies from 4.1 millimetres per hour $(\mathrm{mm} / \mathrm{hr})$ to $22 \mathrm{~mm} / \mathrm{hr}$ for 72 hour and six hour duration events respectively (Institute of Engineers Australia, 1987).

The monthly rainfall data for the first year post rehabilitation is shown in Figure 4, a generally lower than average year compared to the average monthly rainfall shown in Figure 2.

Regional wind data indicates that winds are predominantly from the west to northwest during summer and from the southeast for the remainder of the year. Wind speeds recorded at the Telfer airstrip for the entire year are generally light to moderate (under $20 \mathrm{~km} / \mathrm{hr}$ ). 


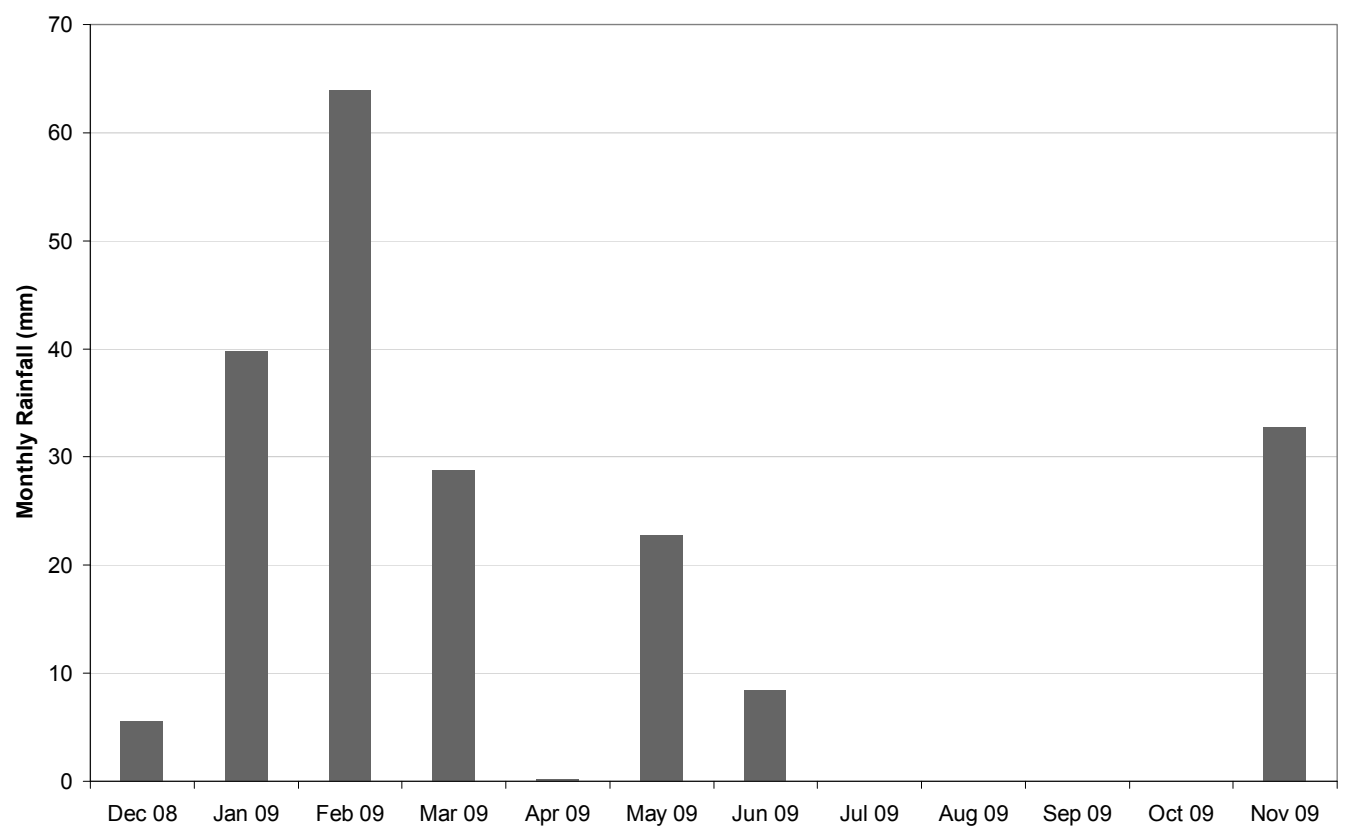

Figure 4 Monthly rainfall totals for Telfer, December 2008 to November 2009

\subsection{Drainage and water resources}

No significant surface drainage channels occur within the project area other then ephemeral drainage lines that are generally poorly defined and only extend for short distances, due to the sandy soils. Most drainage is by sheet flow over the surface, which rapidly dissipates into the sandy soils.

Water accumulates in small clay pan areas, which have distinctive vegetation due to the presence of ephemeral ponds that develop after rainfall.

\section{$2.5 \quad$ Pit 13}

Pit 13 is located within ML M45/11 Fallows Field approximately $8 \mathrm{~km} \mathrm{SW}$ from the main Telfer mine and is accessed via the Pit 13 Haul Road. The Rudall Creek Road skirts Pit 13 and on the western edge of the waste rock dump, Figure 5.

Around 791,800 t of ore was mined from Pit 13 between 1986 and 1995. Ore processing took place at the main Telfer site therefore no infrastructure such as tailings storage facilities occur at Pit 13, apart from the open pit and the waste rock dump (WD13).

The vegetation on the sand plains around Pit 13 is dominated by scattered shrubs of Acacia ancistrocarpa with groves of $A$. monticola and patches of $A$. translucens and A. wanyu, Hart (1997). Hard spinifex Triodia basedowii, with smaller numbers of $T$. pungens and Plectrachne schinzii form the understory and occupy much of the open sand plains. The adjacent stony hills have scattered Eucalyptus leucophloia (Snappy Gum) over shrubs of Acacia translucens and groves of $A$. wanyu, with an understory of hard spinifex Triodia basedowii and T. pungens. 


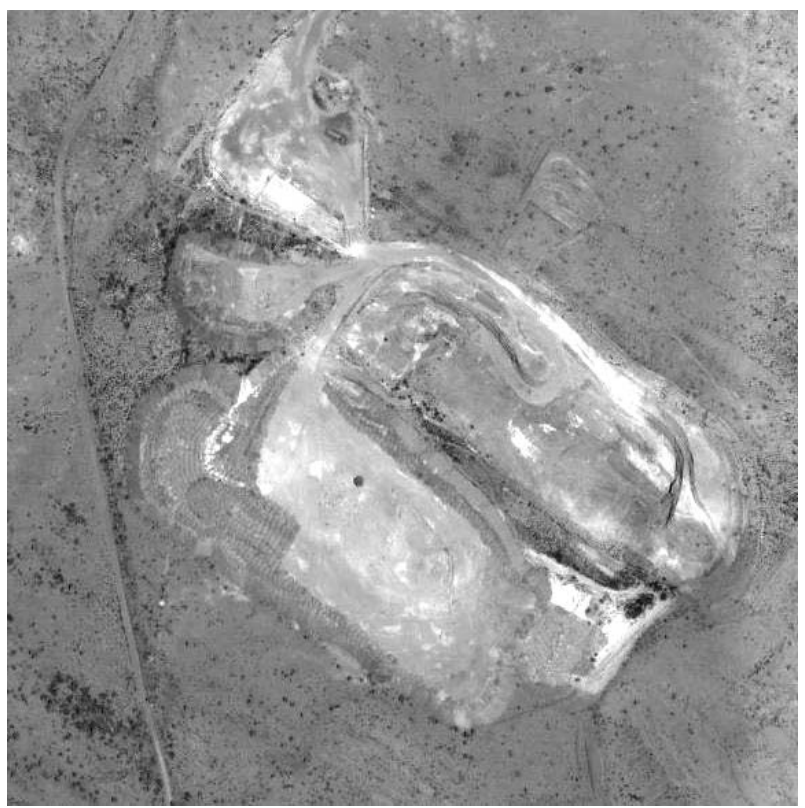

\section{Figure 5 Aerial view of Pit 13 (pre-rehabilitation)}

\subsection{Closure obligations}

Telfer Gold Mine plans to meet the Environmental Protection Agency's environmental objective:

"To design and construct waste rock dumps that are compatible with the regional physiography; stable in the long term and do not present ongoing acid mine drainage risks. "Minister for the Environment and Heritage. Statement approval (No. 606) Condition 8.

To this end the aims of the rehabilitation program for Pit 13 are to:

- maintain the integrity, ecological functions and environmental values of the soil and landform

- maintain the quantity and quality of surface waters such that existing and potential environmental values and ecosystems are maintained and ensure no post-mining discharges of contaminants

- maintain the abundance, species diversity, geographical distribution and productivity of ecological communities and protect rare and priority flora and fauna

- leave the post-mining landscape in a condition safe for humans and animals

- ensure that mining wastes are contained within appropriately designed and monitored dumps to minimise the potential for sediment discharge, acid rock drainage and/or leaching of metals

- ensure that changes to the biophysical environment do not adversely affect historical and cultural associations and comply with relevant legislation (and meet the requirements of any agreements)

- construct stable landforms that are compatible with the local surrounding landscape and ensure the long-term containment of mining wastes.

\section{Construction of mesa landform}

The information from the waste rock characterisation and site geographic and ecological survey was evaluated using a risk assessment method. The risk based approach ensured that potential health, safety and environmental issues were paramount in the landform design. A detailed engineering plan was prepared based the rehabilitation objectives outlined in the previous section. The plan included cut and fill volume calculations on every $50 \mathrm{~m}$ chainage to make sure that earthmoving contractors moved sufficient material to ensure that the planned shape was achieved with available materials. The following sections describe how each environmental aspect was addressed during construction. 


\subsection{Vegetation and fauna}

A fauna survey focusing on bilby habitats was undertaken by Telfer environmental staff to ensure that no fauna were endangered by the harvesting of topsoil and the subsequent push of the dump toe. No Bilby habitats were found and the work was given a land clearance and surface disturbance permits.

A vegetation survey was undertaken by the project supervisor to generate a list of species that may have contributed propagules (seeds and pieces of live vegetation with the potential to strike), Table 1.

During construction the operator and site environmental supervisor worked together to protect flora and fauna, for example Figure 6 shows a goanna that was sheltering in a crevasse on WD13, the environmental supervisor informed the operators who waited until it moved away before they filled the crevasse.

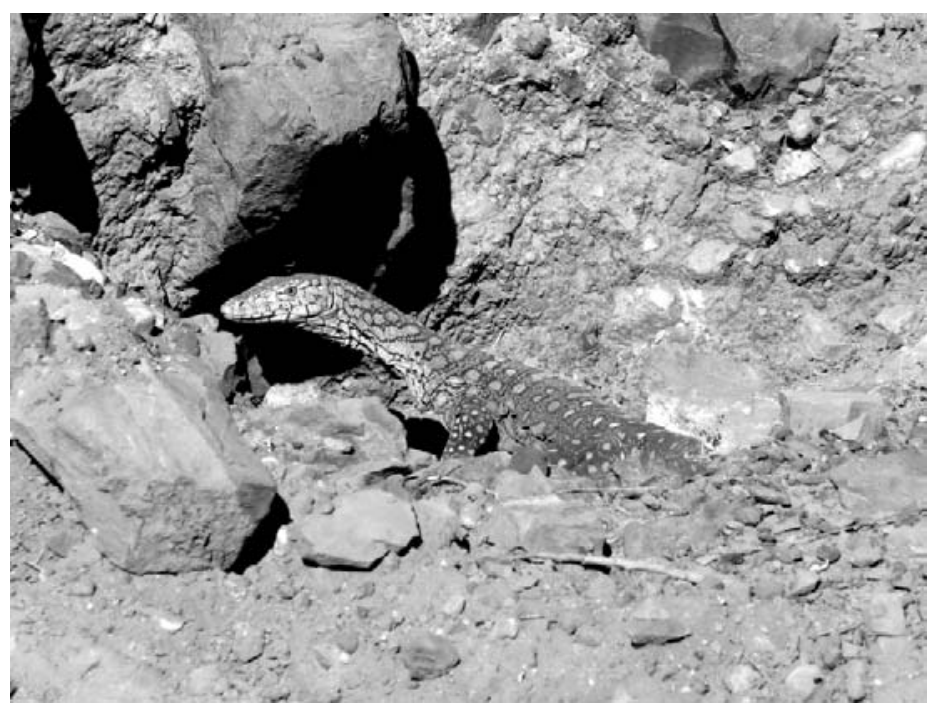

Figure 6 Goanna on WD13

Table 1 Plants found at the toe of WD13

\begin{tabular}{llll}
\hline Genus & Species & Genus & Species \\
\hline Acacia & Ancistrocarpa & Eucalyptus & Kingsmillii \\
Acacia & Pyrifolia & Eucalyptus & Odontocarpa \\
Acacia & Aneura & Gossypium & Australe \\
Acacia & Monticola & Grevillea & Wickhamii \\
Acacia & Stipuligera & Grevillea & Stenobotrya \\
Acacia & Translucens & Hakea & Lorea Subsp. Lorea \\
Acacia & Ayersiana & Senna & Artemisioides Subsp. Oligophylla \\
Anthobolus & Leptomerioides & Solanum & Centrale \\
Cassia & Sturii & Stylobasium & Spathulatum \\
Cassia & Glutinosa & Tribulus & Suberosus \\
Corymbia & Opaca & Triodia & Pungens \\
Eremophila & Sp. Longafolia & Triodia & Basedowii \\
\hline
\end{tabular}

\subsection{Topsoil removal and storage}

A D10 bulldozer was used to push the top $25 \mathrm{~cm}$ soil to a local stockpile within the surveyed toe into stockpiles (Figure 7). The intention was to harvest as much topsoil as possible with the least amount of 
impact on the vegetation. This was achieved by avoiding large trees that were near the boundary of the surveyed toe. In practice it was not difficult to work around trees on the clearance boundary and this did not appear to cause significant reductions in the volume of topsoil harvested.

An 850 excavator and 777 dump trucks were used to transfer the topsoil from the toe of the dump to a designated storage location in the centre of WD13. The central zone of WD13 was cleared of weeds (next section) and levelled prior to topsoil carting to avoid costly double handling, minimise weed contamination and the loss of topsoil in windy conditions.

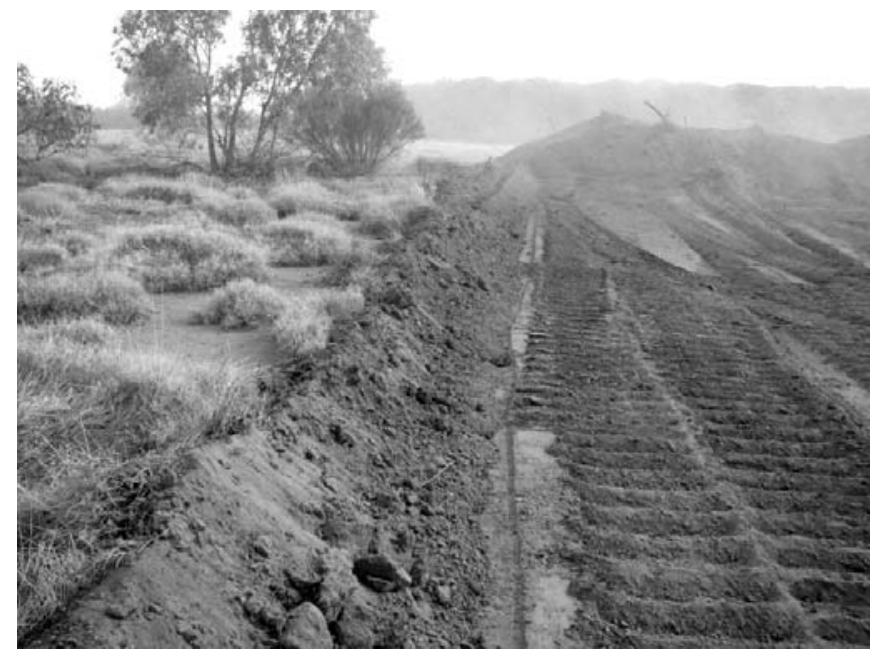

\section{Figure 7 Topsoil harvesting}

\subsection{Surface preparation}

\subsubsection{Weeds}

A D10 and a grader were used to remove the weeds mainly Athel Pine or Tamarisk (Tamarix aphylla) and Kapok bush (Aerva javanica) from the waste dump surface. Around five Athel Pines were buried in holes dug next to the trees (Figure 8).

The predominant weed was Kapok bush at the time it was mostly in seed. The weeds and rubble were pushed into small piles around fissures for the burial. Kapok bush were seen growing amongst the end dumped waste rock and on the north face of WD13, which could not be reached by the grader (Figure 9). Although the grader was successful in removing and burying around $95 \%$ of the weed some seeds would have dispersed over freshly prepared surfaces from the hard to get plants in the rock stockpiles and on the north face.

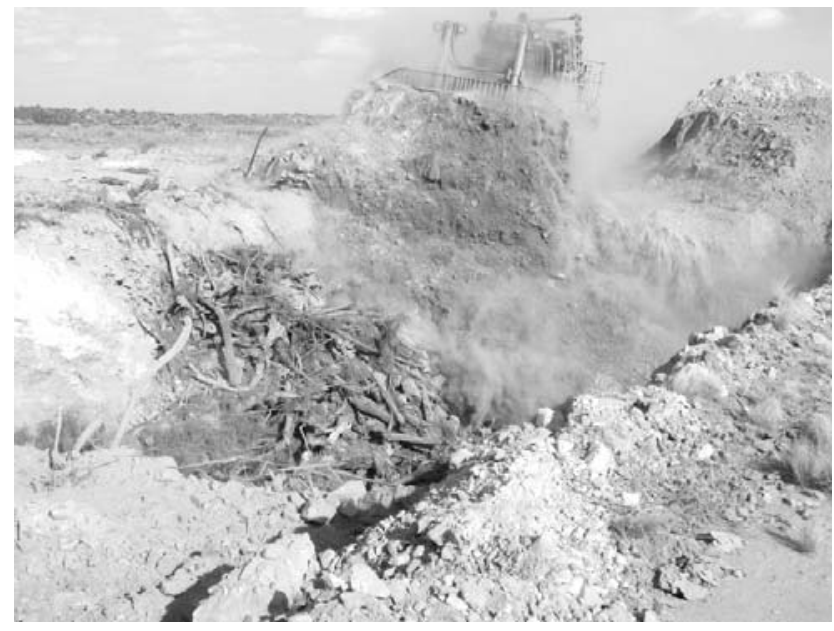

Figure 8 Burying of Athel Pine 


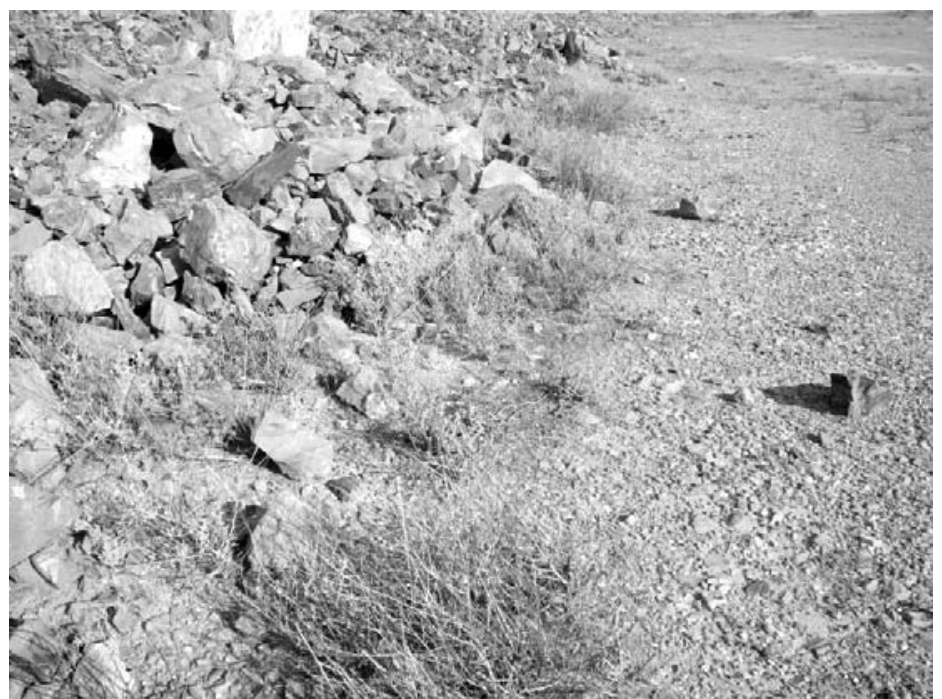

Figure 9 Kapok weed growing in difficult to reach places

\subsubsection{Paddock dumped waste rock}

A D10 bulldozer was used to relocate waste rock that had been paddock dumped during mining operations (Figure 10). Very large rocks, some the size of a small car were relocated to the Pit 13 access ramp. The remainder were either placed strategically for later use as hummock material on the dump surface or incorporated in the perimeter bund.

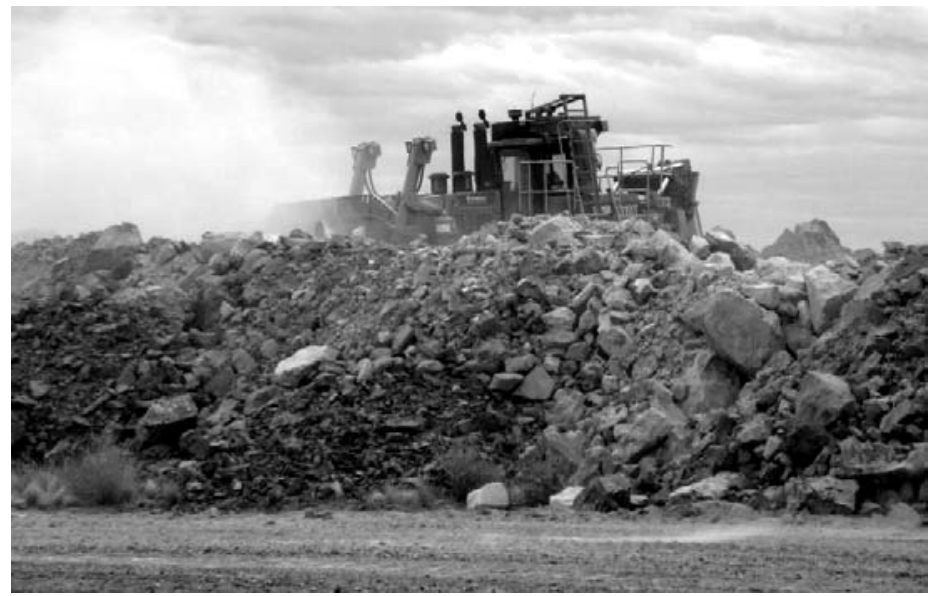

Figure 10 D10 bulldozer used to push waste rock stockpiles

\subsubsection{Drainage}

After a detailed geotechnical survey by Telfer geotechnical engineers the concerns regarding tunnel erosion were allayed and the surface was designed to be internally draining using hummocks to minimise pooling of water on the surface and creating microhabitat for vegetation. Telfer geotechnical engineers considered that by redirecting surface runoff away from the dump face by internal drainage met the environmental commitments because this reduced the likelihood of overtopping, while the risks of piping erosion was low.

\subsection{Mesa land forming}

The design criteria were met with some variations from the original construction plan to accommodate the earthmoving contractors work plan. This did not significantly alter the final appearance or structural integrity of the rehabilitated dump. The following subsections provide detail on how the design criteria were met. 


\subsubsection{Mesa slope angles}

The 16 and $7^{\circ}$ slope angles were achieved using a D10 equipped with an inclinometer. Unfortunately, GPS equipment was not available in time for the work, which resulted in additional demand on surveyors.

Despite this minor setback the design slopes were generally achieved to within $\pm 1^{\circ}$ (Figure 11). The net effect was that the final mesa landform was visually similar to the surrounding topography (Figure 12).

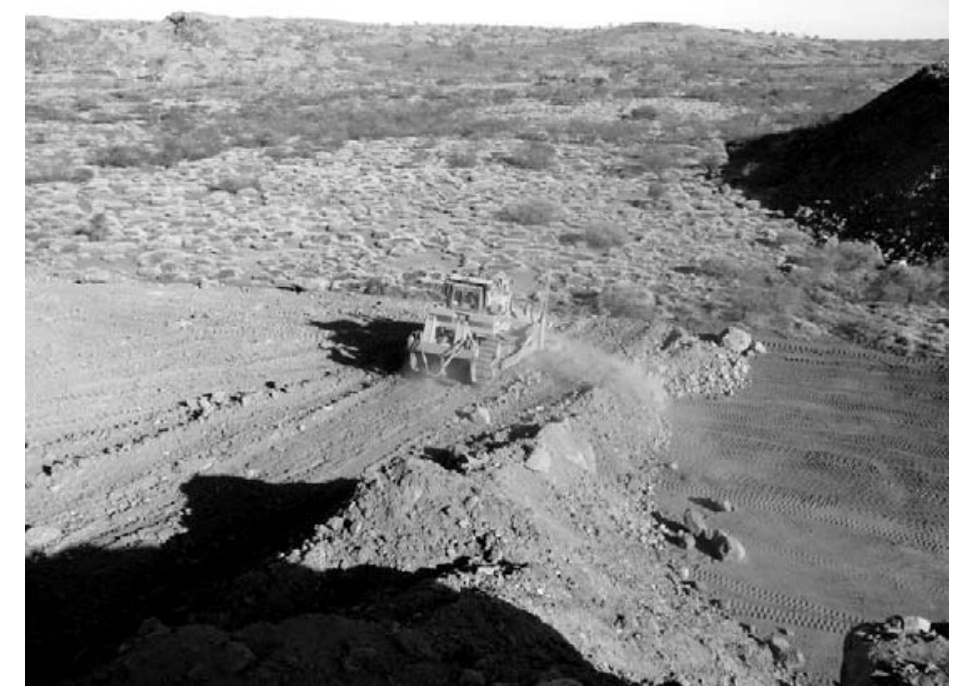

Figure 11 D10 bulldozer pushing lower slope of constructed mesa landform

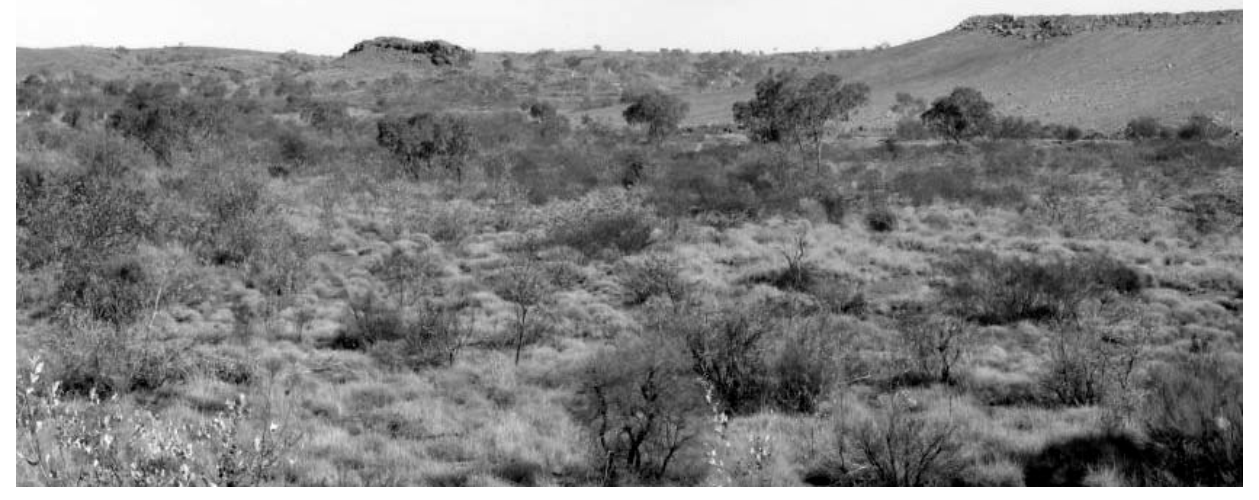

Figure 12 Final constructed mesa landform (natural mesa on left)

\subsubsection{Armouring and topsoil}

The most effective way of placing rock armour and topsoil on the face of WD13 was to place the materials in the required ratio on the rim for the D10 to work down the face. This process was very effective, the only drawback was the presence of a significant number of large rocks which required a considerable effort to sort prior to loading the $777 \mathrm{~s}$.

The final rock armour/topsoil mix worked well and was similar to earlier trials by Telfer at WD10. The topsoil was well mixed with the rock armour providing the best combination for protection from erosion and rapid establishment of vegetation from the topsoil seed bank.

\subsubsection{Rock perimeter bund on shoulder of WD}

A 2 to $2.5 \mathrm{~m}$ rock bund was constructed around the perimeter of WD13 shoulder. This bund gave a visual effect similar to a mesa duricrust (Figure 12). No topsoil was used in the perimeter bund. 
The construction of the perimeter bund resulted in a few large boulders rolling down the face of the dump. This may have been avoided if more time was taken to carefully place the rocks and to selectively pull the larger rocks away from the face. These rocks were removed by a long reach excavator or pushed down the face by a dozer.

\subsection{Dump surface}

Loaders (988 and 966) were used to construct the soil and waste rock hummocks on top of WD13. The loaders and dump trucks worked efficiently together in constructing the hummocks to the design criteria. The hummocks were placed on the weed free surface fitting to the existing topography, Figure 13.

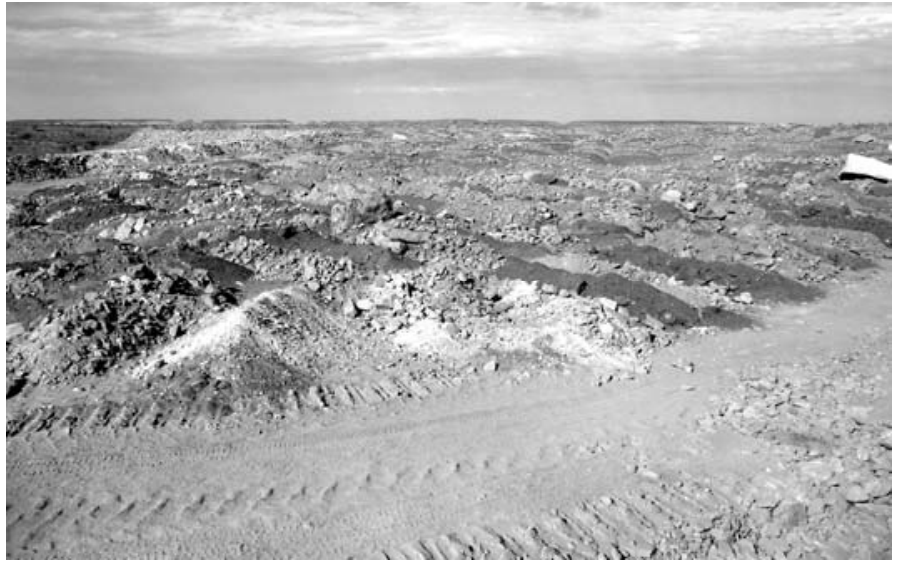

Figure 13 Surface soil and waste rock hummocks

\subsection{Final touches}

This section describes the actions taken to complete the constructed mesa to a high standard. This includes the construction of an access track and the removal of boulders from the face of WD13 and tidying unintended construction site disturbances.

\subsubsection{Access track}

A $3 \mathrm{~m}$ wide access track with two turn-around points was built with a grader to allow access to Telfer personnel and contractors for site inspections and rehabilitation monitoring (Figure 14). The access track was built on the inside of the perimeter bund as shown in the construction plan. The track should allow access to light vehicles but is not suitable for trucks.

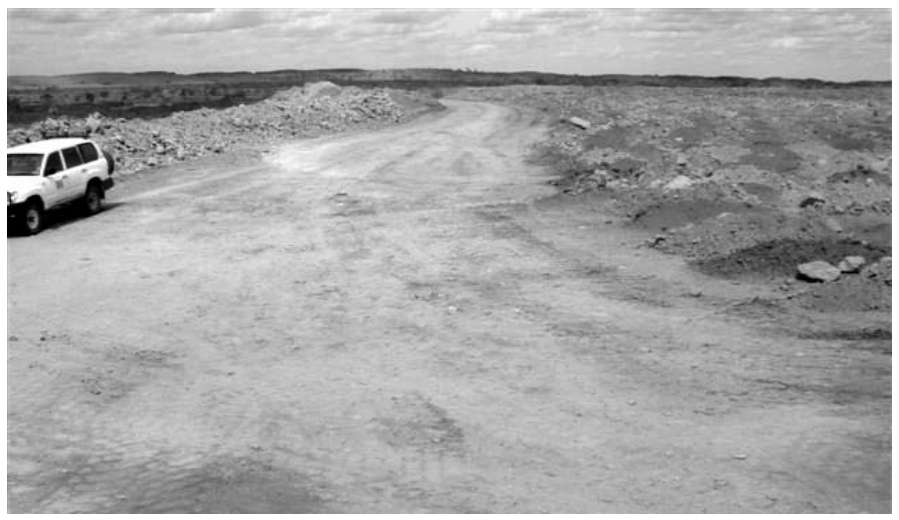

Figure 14 Access track turnaround point (between perimeter berm and hummocks)

\subsubsection{Removing boulders and making good}

As stated earlier, some large boulders rolled down the face of the dump. Whilst large boulders can be seen on some natural mesa Landforms it was decided to remove these boulders for aesthetic and safety reasons. A 
D10 was used to push the boulders to the toe of the dump and repair any damage to the rock armouring. Some unavoidable damage to the Rudall River Road berms occurred in removing the boulders (Figure 15). This berm was repaired after the boulders were properly tucked into the toe of the dump.

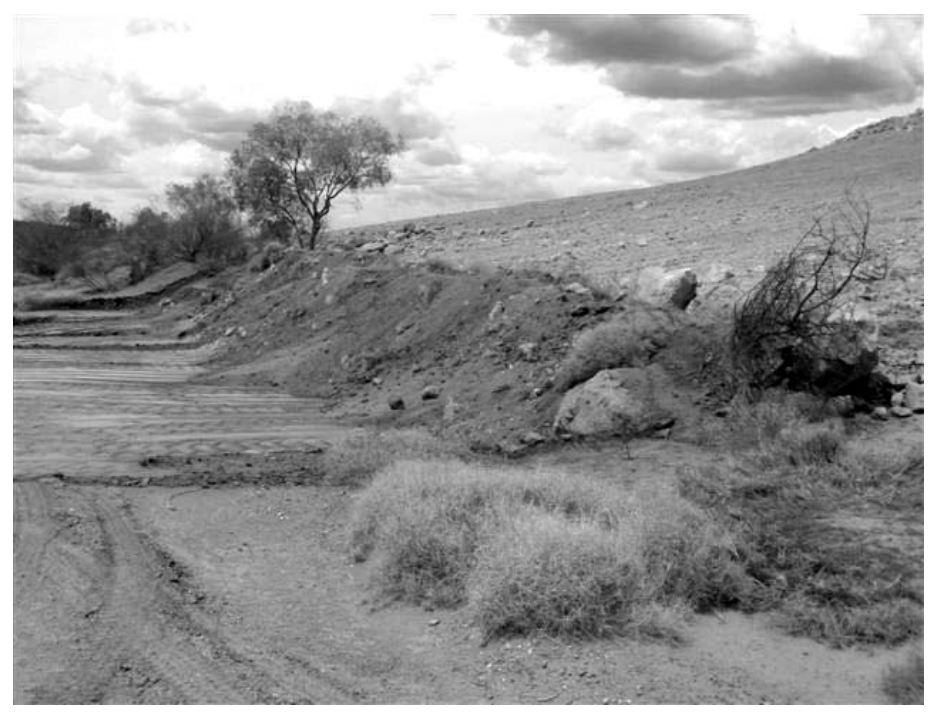

Figure 15 Repairs to shoulder of Rudall River Road

\section{$4 \quad$ Monitoring program}

A comprehensive five year monitoring program has been implemented for the constructed mesa at Telfer WD13. This program consisted of photo monitoring points, soil quality sampling grid, ecosystem functional analysis (EFA) transects and continuous remote monitoring of soil moisture with a tipping bucket rain gauge.

The baseline survey was undertaken in December 2008 immediately after construction. The first monitoring run was undertaken in October 2009. The main observations were:

- Photo point monitoring and soil quality sampling have provided evidence of structural and chemical stability of the mesa landform (Figure 16).

- The EFA monitoring documented minor erosion on the mesa slope, consistent with expectations.

- The dominant native vegetation found on WD13 in year one was spinifex (Triodia Sp.) the vast majority being the soft spinifex (Triodia pungens) followed by T. basedowii and T. longiceps and a Bluebush species (Figure 17). Acacia species identified on transects were Acacia ancistrocarpa, $A$. aneura var. aneura, A. pyrifolia and A. maitlandii.

- Grevillea wickhamii was recorded on both the slopes and hummocks (Figure 17). Atalaya hemiglauca, Corchorus lasiocarpus and Tribulus suberosus were noted; Ptilotus calostachyus, Ptilotus exaltatus, Ptilotus obovatus and Solanum lasiophyllum were also prevalent.

- The vegetation was in early growth stages and suffering from heavy grazing, camels were observed on WD13 during the monitoring program.

- Kapok bush was the only weed recorded but it was by far the most dominant plant species on WD13.

While these changes appear to be only minor over the baseline survey, this work clearly demonstrates that the monitoring program will provide several measures to track the evolution of the rehabilitated waste rock dump. It is also evident that this monitoring program will provide a sound basis for Telfer to determine the site 'hand-over' point.

Further comparisons over baseline and other rehabilitation work elsewhere at Telfer will be drawn in subsequent years to provide Telfer with a sound management tool for planning the future rehabilitation of the waste rock and tailings storage facilities. 

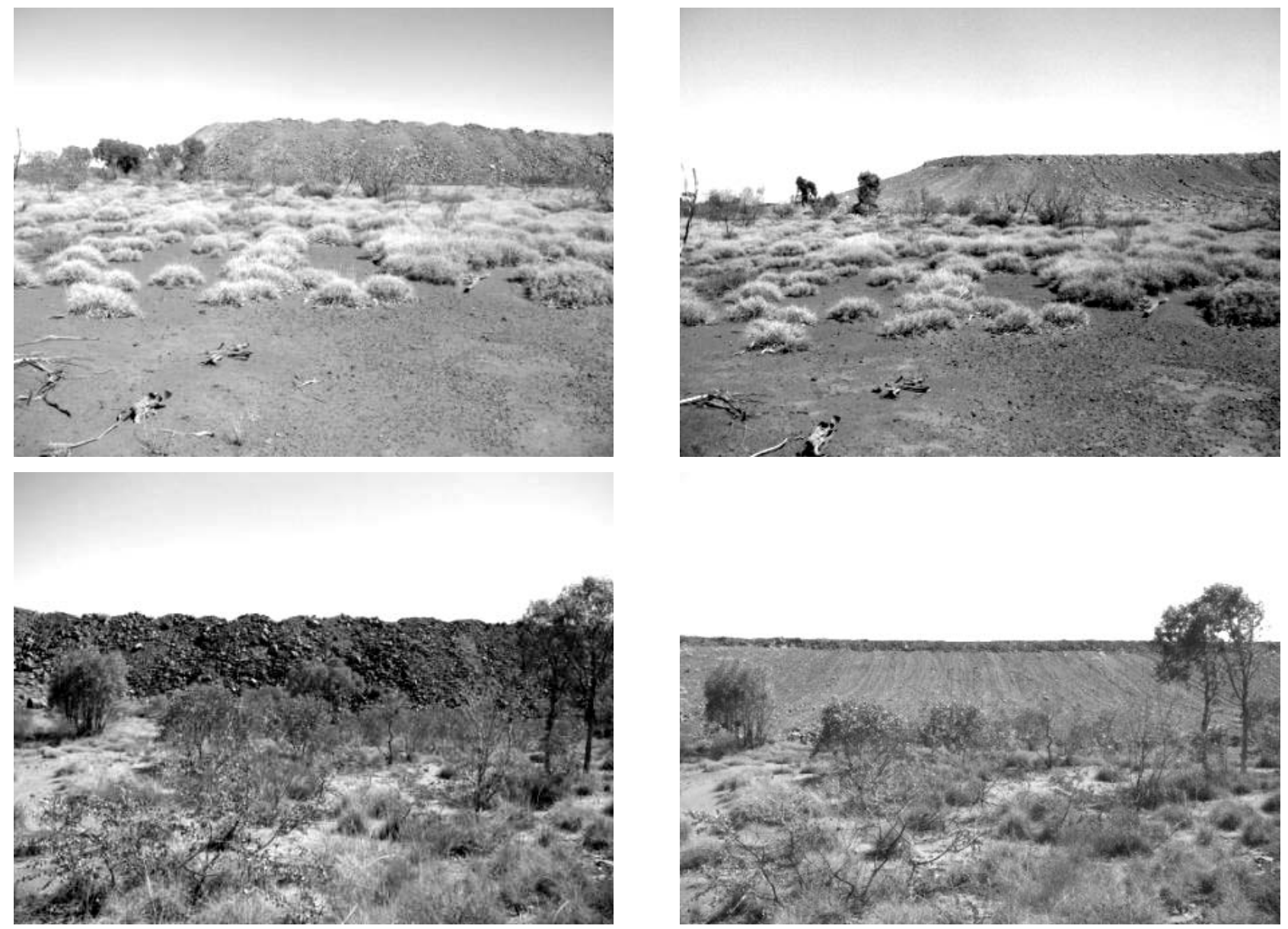

Figure 16 Before and after photo monitoring points: photos on left taken in November 2008; photos on right taken in October 2009
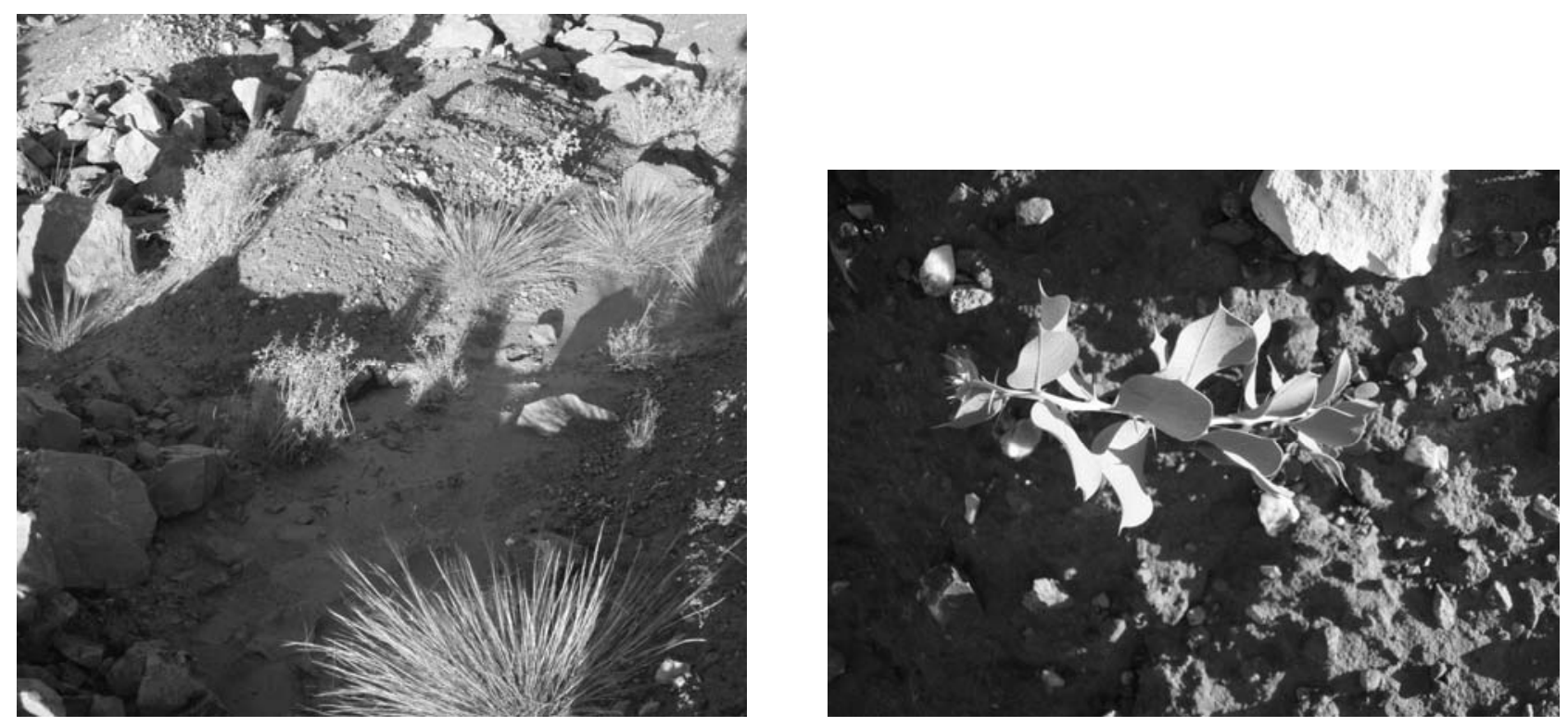

Figure 17 Photograph of two plant species (left: Native grasses (Triodia pungens); right: Grevillea wickhamii) growing on the constructed mesa landform at Pit 13, June 2010 


\section{$5 \quad$ Challenges and lessons}

During the construction phase several challenges were recorded for future rehabilitation works, these were:

- Lack of historic information on materials in mine waste stockpiles, a common feature of old waste dumps resulted in an unexpected large amount of rocks $>1 \mathrm{~m}^{3}$ on the surface of WD13. These were relocated strategically to fill gaps in the dump wall, reinforce the safety bund around Pit 13 and to block disused access tracks. A contingency plan for additional handling of such materials needs to be included in all rehabilitation plans, based on the same lines as those undertaken in this work.

- The distance travelled between the project and the source of water required for dust suppression resulted in delays and more frequent breakdowns of the water trucks. Heavy vehicles were stood down when visibility was poor to eliminate incidents. Where possible rehabilitation projects should use water resource close to project to avoid downtime.

- For operational reasons the earthmoving contractor for operational reasons elected to start in the opposite direction to the engineer's design cut/fill calculations. This resulted in poor control of cut and fill volumes, which required additional handling. It is highly recommended that contracts include a clause requiring the contractors prior to making deviations from design to consult the design engineers to confirm that the proposed changes will be compatible with the original plans.

- Heat was generally over $40^{\circ} \mathrm{C}$ making working conditions difficult. This is typical of the region and adequate precautions were taken to minimise the effect of heat.

- The SW corner of WD13 was constrained by the instruction to avoid realigning the Rudall River Road. This resulted in very little margin for the earthmoving contractors to work in. In future small road realignments should be considered.

- The engineering plan had inaccurate survey information for the northwest and northeast quadrants of WD13; this resulted in modifications to the plan on the go. This contributed to a surplus or deficit of materials in these areas. In future site surveys should be undertaken immediately prior to the engineering design to provide the most up-to-date information.

- Placement of hummocks on a large scale can be more cost effective than the traditional $10 \mathrm{~cm}$ flat topsoil layer combined with ripping; however, this method needs further refinement if it is to be included in future rehabilitation.

- The demonstration plots constructed on WD11 and WD9 enabled contractors to visualise the end result, this familiarisation process is highly recommended for future site rehabilitation at Telfer.

The lessons learnt in the 2009 monitoring program are:

- Native species will germinate given suitable rains in a mix of topsoil and waste rock material.

- Scraping the surface to remove Kapok bush was not effective in removing the seedbank; future weed control will need to be modified to ensure a much better control strategy for the seed bank. It is recommended that if weeds are present, weed eradication should start at least two years before rehabilitation.

- The slopes on the WD13 constructed mesa closely mimic the natural analogue and appear to be stable.

- Dozer scrape marks and scouring by large rocks on the face of the constructed mesa are a potential source of erosion; negligible erosion occurred during the first year after construction.

- An animal management program should be implemented to control graziers like camels particularly during the early growth stages to give plants a chance to establish.

\section{$5.1 \quad$ Achievements}

- The Topsoil budget was to the plan. This reinforces the need to continue monitoring and tracking topsoil and treating the material as a valuable resource. 
- Harvesting and spreading topsoil over the revegetation area in one operation reduced double handling and likely resulted in more effective revegetation because the seed was more viable than old or deeply buried seed and the soil was more fertile than stockpiled topsoil.

- Excess waste rock was used in a constructive manner to address minor issues such as filling the south east dog leg corner and extra filling of low spots on WD13.

- Communication between the earth moving contractor (Exact), the client (Telfer Environment) and mine rehabilitation specialists (COOE) lead to open exchange of information and increased problem solving by tapping into the collective experience.

- Slope angles were within $2^{\circ}$ of target angle.

- The work was completed without injury or incident.

- The final landform was stable and ascetically pleasing.

- The project was completed on schedule, before December 2008.

\section{Summary}

The Pit 13 mesa Rehabilitation Project was completed on time and without incident or injury. The project ran relatively smoothly with good solutions for unexpected issues such as machinery failure, large volume of oversize rocks and impromptu deviations from engineering design. Other difficulties that were confronted were solved promptly through consultation. Some issues require further monitoring and research including the management of Kapok bush and refining or revisiting the use of hummocks.

Overall this work demonstrates that Telfer is well on the way to meeting the licence conditions (Minister for the Environment and Heritage, Statement of Approval No. 606, Condition 8):

"To design and construct waste rock dumps that are compatible with the regional physiography; stable in the long term and do not present ongoing acid mine drainage risks."

The ongoing rehabilitation monitoring of Pit 13 will help to demonstrate the physical and chemical stability of the mesa landform design in the long-term. It is expected that the monitoring program will provide feedback to Telfer on any refinements to the mesa landform rehabilitation technique and to identify if any future works are required to maintain the constructed mesa at WD13.

\section{References}

Beard, J.S. (1980) A new phytogeographic map of Western Australia, Western Australian Herbarium Research Notes 3: 45.

Hart, R. (1997) Section 1.7 in Notice of Intent Satellite Pit Operation - Fallow's Field Prospect Telfer District, WA. Addendum No. 1, By Newcrest Mining Limited, Telfer Gold Mine, October 1997.

Institution of Engineers Australia (1987) Australian Rainfall and Runoff - A Guide to Flood Estimation, Revised Edition. 
